\title{
PREDICTION OF THE VOLTAGE QUALITY IN AN OVERHEAD TRANSMISSION LINE WITH DISTRIBUTED PARAMETERS
}

\author{
Leonid L. Bulyga ${ }^{1}$, Evgeniy V. Tarasov ${ }^{1}$, Vasily Ya. Ushakov ${ }^{1, \text { a }}$, Nikolay N. Kharlov ${ }^{1}$ \\ ${ }^{1}$ Department of Power Grids and Electrical Engineering, Institute of Power Engineering, National Research Tomsk \\ Polytechnic University, Tomsk 634050, Russia
}

\begin{abstract}
The present work is devoted to investigation of an electrical transmission line with allowance for distributed parameters. From the results of voltage measurements at terminals of an actual transmission line, effective values of the voltage are calculated for every line section. Special attention is given to higher harmonics and asymmetry. Spectral composition of the voltage is presented and changes in values of harmonic components are analyzed. The effect of higher harmonics on the equipment operation is analyzed.
\end{abstract}

\section{Introduction}

Technology of any production process depends largely on the energy quality. Low energy quality is manifested through changes in energy supply distorting the normal regime of the production process or causing damages to the electrical equipment. High quality of the electric power supply can be provided by generation of high-quality electric power and its transmission through reliable electrical transmission lines.

\section{Epures of voltages of $n$-harmonics and spectral composition of the voltage of a single-circuit ETL}

Electric circuits are typically characterized by lumped parameters when only electric and magnetic fields localized inside of a capacitor or an inductive coil is considered together with resistor power losses. However, this approach is inapplicable to an electrical transmission line (ELT) in which currents, voltages, and losses are non-uniformly distributed along the entire line.

In the present work, the problem of prediction of the effective voltage with increasing distance from the measurement site was analyzed to estimate the quality of the electric energy in the line considering the distributed parameters. The effective values of the voltage were calculated based on measurements on terminals of a $110 \mathrm{kV}$ real one-circuit ELT $70 \mathrm{~km}$ long. The data shown in the figures were processed using the program complex developed at the Regional Energy Saving Center. A mathematical model of the multiwire ELT described in [2] was used.

As shown in Fig. 1, the effective voltage changes in each section of the line. From the figure it can be seen how the voltage changes with increasing distance from the measurement site.

${ }^{a}$ Corresponding author : rcr@tpu.ru 


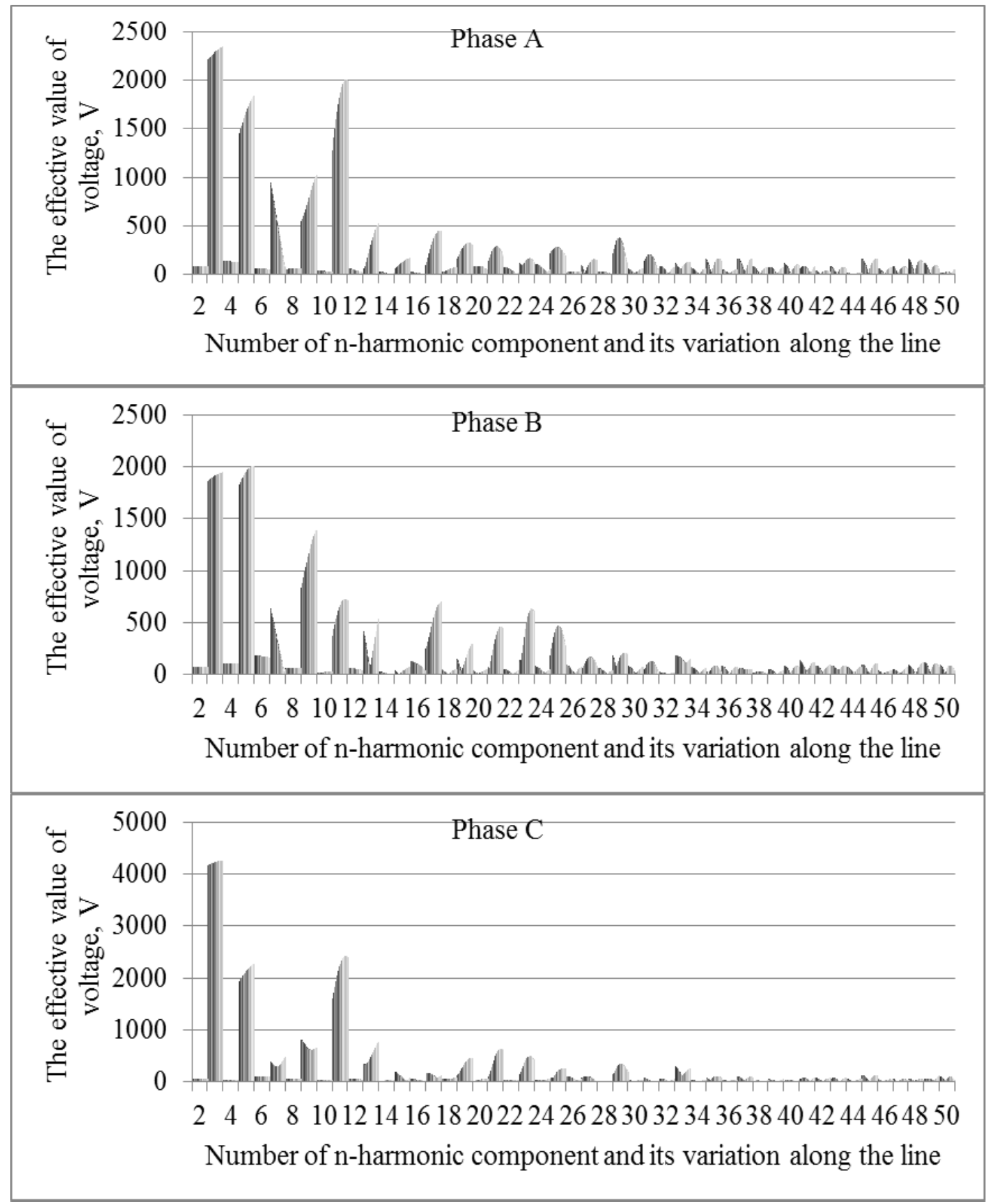

Figure 1. Epures of voltages of n-harmonics along the transmission line with distributed parameters

New GOST 32144-2013 "Electrical Energy. Electromagnetic Compatibility of Technical Means. Quality Standards on Electric Energy in Power Supply Systems of General Designation" sets the permissible values for the coefficients of the harmonic voltage components.

Figure 2 shows the harmonic structure of the voltage from the beginning to the end of the line. For the 5 th and 11th harmonics, the coefficients of the harmonic voltage components were $\mathrm{K}_{\mathrm{U}(5)}=1.5 \%$ and $\mathrm{K}_{\mathrm{U}(11)}=1 \%$. These coefficients at the beginning of the line exceeded their permissible values 
according to GOST, and at the end of the line increased to $2.29 \%$ and $2.42 \%$, respectively. Similarly, the 3rd harmonic exceeded the permissible value $\mathrm{K}_{\mathrm{U}(3)}=1.5 \%$ and increased to the end of the line.

The coefficients for the harmonic components of the 9th and 21 st harmonics were $\mathrm{K}_{\mathrm{U}(9)}=0.4 \%$ and $\mathrm{K}_{\mathrm{U}(21)}=0.2 \%$. Both harmonics increased with distance from the measuring site, with the only difference that the measured 9th harmonic exceeded its permissible value and increased with distance, whereas the voltage limit for the 21 st harmonic was exceeded closer to the end of the line.

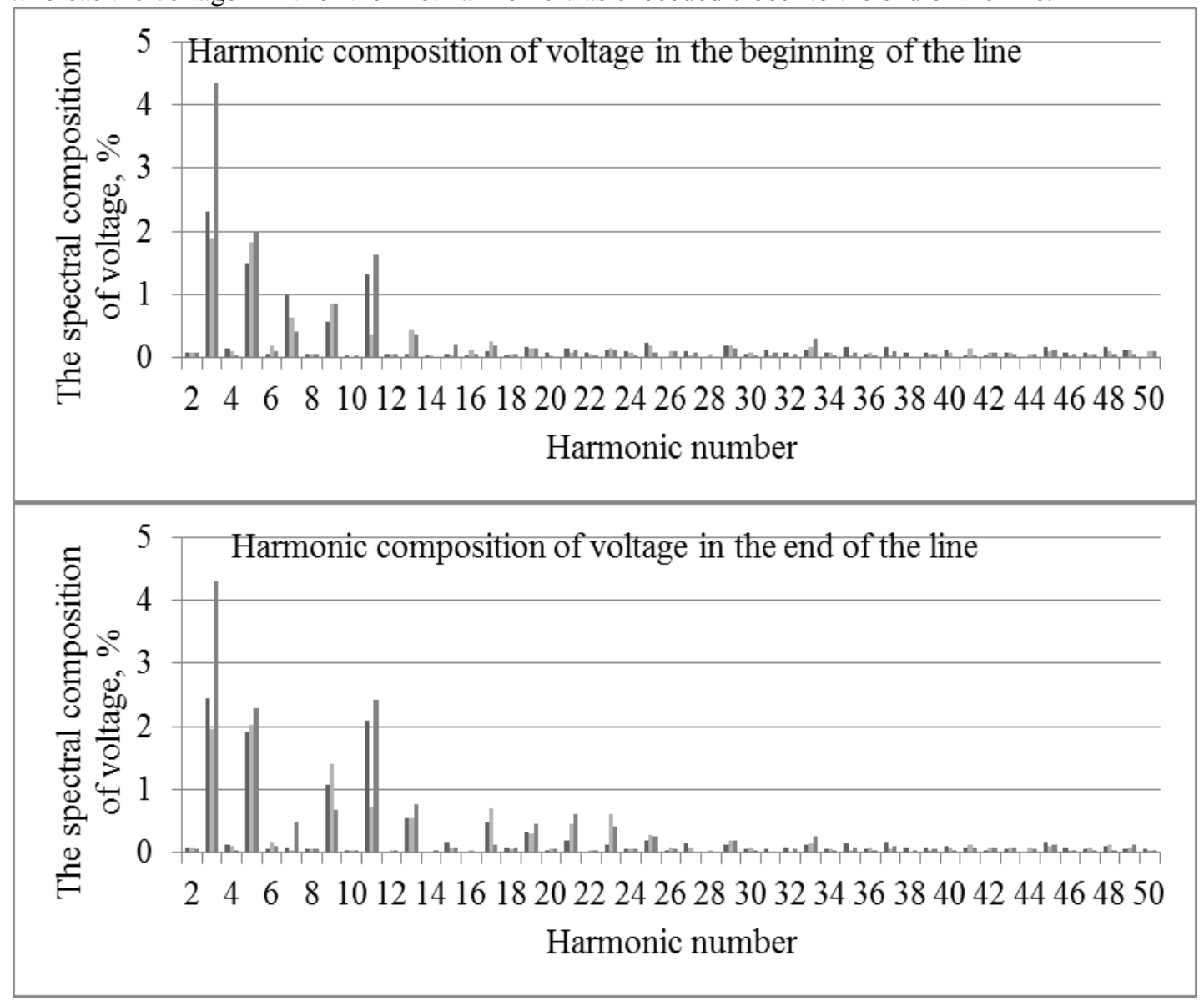

Figure 2. Spectral composition of the voltage in the single-circuit transmission line with distributed parameters

Due to the increasing harmonic components, the asymmetry arose at higher frequencies. The line operation was influenced by the 3rd, 5th, 9th, 11th, and 21 st harmonics. These harmonics exceeded their permissible values and differed in phases, thereby increasing the asymmetry. The presence of the asymmetry in the line at higher frequencies may result in its incorrect operation, for example:

- false triggering of automation and relay protection systems,

- additional losses of electricity,

- accelerated wear of insulation,

- increase in the instrumental and energy accounting errors,

- shutdown or failure of capacitor units.

The above-listed items characterize the electromagnetic loss components. The technological loss components are also present, namely [1]:

- decrease in the productivity of the equipment and technological process,

- increased power consumption,

- decrease in the efficiency of the equipment. 


\section{Conclusions}

1. Epures of the voltage have given an idea of the change of the efficient voltage along the line and have demonstrated its difference from the value at the measurement site.

2. Higher harmonics influence the operation of the equipment of the line at cause additional energy losses. They also can be the reason for increased energy consumption and decreased efficiency of the equipment.

\section{References}

1. Ushakov V.Ya. Modern problems of electric power industry (Publishing House of Tomsk Polytechnic University, Tomsk, 2014)

2. V. S. Bobrovnikov, M. V. Volkov, V.V. Ivanov, et al. Operating parameters of $110 \mathrm{kV}$ electric networks in the South of Russia providing efficient energy transport (STT Publishing, Tomsk, 2013)

3. Kartashev I.I., Tul'skii V.N., et al. Electric power quality management (Moscow: MEI Publishing House, 2006)

4. Yu.S. Zhelezko, A.V. Artemyev, O.V. Savchenko. Calculation, analysis and valuation of losses in electric networks (Publishing House of NTs ENAS, 2003) 